\title{
Biochemical Barriers on the Path to Ocean Anoxia?
}

Stephen Giovannoni ${ }^{\mathrm{a}^{*}}$, Francis Chan $^{\mathrm{b}^{*}}$, Edward Davis $^{\mathrm{c}}$, Curtis Deutsch $^{\mathrm{d}}$ and Sarah Wolf ${ }^{\mathrm{a}}$

*The first and second authors shared equally in developing this manuscript a\#Department of Microbiology, Oregon State University, Corvallis, OR, USA

${ }^{\mathrm{b}}$ Department of Integrative Biology, Oregon State University, Corvallis, OR, USA

${ }^{\mathrm{c}}$ Center for Genome Research and Biocomputing, Oregon State University, Corvallis, OR, USA

${ }^{\mathrm{d}}$ University of Washington, School of Oceanography, Seattle, WA, USA

Running title: Hypoxic Barrier Hypothesis

Word count: 3,265

Mailing address: Department of Microbiology, Oregon State University, 220 Nash Hall, Corvallis, OR 97331; Phone: (541) 737-1835; Fax: (541) 737-0496.

mBio: Opinions/Hypotheses

Corresponding author: steve.giovannoni@oregonstate.edu

\section{ABSTRACT (154/250 words)}

The kinetics of microbial respiration suggest that, if excess organic matter is present, oxygen should fall to nanomolar levels, in the range of the Michaelis-Menten constants $\left(\mathrm{K}_{\mathrm{m}}\right)$. Yet even in many biologically productive coastal regions, lowest observed $\mathrm{O}_{2}$ concentrations often remain several orders of magnitude higher than respiratory $\mathrm{K}_{\mathrm{m}}$ values. We propose the Hypoxic Barrier Hypothesis (HBH) to explain this apparent discrepancy. The $\mathrm{HBH}$ postulates that oxidative enzymes involved in organic matter catabolism are kinetically limited by $\mathrm{O}_{2}$ at concentrations far higher than the thresholds for respiration. We found support for the $\mathrm{HBH}$ in a meta-analysis of $1137 \mathrm{O}_{2} \mathrm{~K}_{\mathrm{m}}$ values reported in the literature: the median value for terminal respiratory oxidases was $350 \mathrm{nM}$, but for other oxidase types the median value was $67 \mu \mathrm{M}$. The HBH directs our 
24 attention to the kinetic properties of an important class of oxygen-dependent reactions that could

25 help explain the trajectories of ocean ecosystems experiencing $\mathrm{O}_{2}$ stress.

\section{IMPORTANCE (87/150 words)}

27 Declining ocean oxygen associated with global warming and climate change is impacting marine

28 ecosystems across scales from microscopic planktonic communities to global fisheries. We

29 report a fundamental dichotomy in the affinity of enzymes for oxygen. The importance of this

30 observation has yet to be fully assessed, but it is predicted to impact the rate at which organic

31 matter is oxidized in hypoxic ecosystems, and the types of organic matter that accumulate.

32 Competition between intracellular enzymes for oxygen may also have impacted microbial

33 strategies of adaptation to suboxia.

\section{KEYWORDS}

35 oxygen minimum zones, oxygenase $\mathrm{K}_{\mathrm{m}}$, ocean respiration, dissolved organic matter

\section{INTRODUCTION}

37 Marine suboxic and anoxic zones are hotspots of microbially-mediated biogeochemical

38 transformations that regulate the nitrogen budget and air-sea fluxes of greenhouse gases of the

39 global ocean (1). Because dissolved oxygen (DO) also organizes the structure and dynamics of

40 ocean food webs, understanding the processes that regulate expansion of suboxic and anoxic

41 zones in response to past and current climate changes is a pressing challenge (2). Suboxic and

42 anoxic zones are embedded within broader oxygen minimum zones (OMZ) that comprise some

$438 \%$ of the surface area of the ocean. While recent advances in nanomolar-scale DO measurement

44 technologies have enabled precise delineation of the presence of suboxia and anoxia (3), we 
45 contend that a perplexing yet fundamental question has been overlooked. Given our canonical

46 understanding of microbial respiration kinetics, why are suboxia and anoxia not a much more

47 pervasive feature of the ocean's low oxygen zones?

48 Of biological reactions that consume $\mathrm{O}_{2}$, by far the most important, in terms of mass, is carbon

49 respiration. Michaelis-Menten half saturation $\left(\mathrm{K}_{\mathrm{m}}\right)$ constants for respiration are typically very

50 low, on the order of a few nanomolar, although higher values have been reported (4) (Figure 1).

51 Thus, if labile organic carbon, i.e. compounds that readily can be used as a source of electrons

52 for respiration, is delivered in excess to a microbial ecosystem, DO declines at a rate determined

53 by the respiratory capacity of the microorganisms present and the supply of organic matter.

54 Importantly, the minimum DO attainable should reflect the well-described high-affinity,

55 nanomolar scale $\mathrm{K}_{\mathrm{m}}$ of microbial respiratory oxidases (5). Other factors that can influence DO in

56 aquatic ecosystems include: photosynthesis, when light is present; oxygen transport by ocean

57 currents and mixing; diffusion, which can limit respiration, particularly in aggregates of cells;

58 impacts of low oxygen on grazing metazoa (6), which require higher oxygen concentrations than

59 bacteria; non-respiratory biochemical reactions that consume oxygen; and abiotic reactions that

60 consume oxygen (7). Nonetheless, DOM formation and oxidation is the mechanistic centerpiece

61 in our fundamental understanding of microbial-scale processes leading to low oxygen states and

62 predictions of global ocean oxygen dynamics.

63 Eastern boundary upwelling systems (EBUS) represents one of the ocean's most productive

64 biomes. In these coastal ecosystems, oxygen-poor subsurface waters uplifted from the vertical

65 periphery or core of open ocean OMZs receive elevated organic carbon inputs from surface

66 phytoplankton blooms. Figure 2 shows relative water volumes for DO concentrations across

67 these systems. Of the ocean's four major EBUS, only the Peru-Chile Current System in the 
Eastern Tropical Pacific Ocean persistently exhibits DO-deficient states in continental shelf waters. For both Pacific EBUS, there is an accumulation of water volumes below $100 \mu \mathrm{M}$ but a sharp drop-off in volume of waters that reach suboxic $(<5 \mu \mathrm{M})$ or anoxic $(\sim 0 \mu \mathrm{M})$ states in the upper ocean (0-400 m) including continental shelf waters where remineralization and oxygen

72 loss is most active (Fig 2b). The pattern is striking - despite the nanomolar-scale of respiratory

$73 \quad \mathrm{~K}_{\mathrm{m}}$ values, respiration in productive EBUS is able to draw down DO to hypoxic levels but rarely

74 is able to consume the last $10-60 \mu \mathrm{M}$ DO. While the depth of OMZs extends below $400 \mathrm{~m}$, the

75 failure of suboxic and anoxic volumes to accumulate despite the presence of large volumes of

76 hypoxic water persists when we expand our sampling to $1000 \mathrm{~m}$ (Fig 2d).

77 To explain the observations in Figure 2, we propose the Hypoxic Barrier Hypothesis (HBH), which states: dissolved $\mathrm{O}_{2}$ kinetically limits the activity of oxygenase enzymes involved in the breakdown of organic matter, in the range of oxygenase $K_{m}$ values (median value $67 \mu M$ ) causing a decline in DOM oxidation rates in ecosystems experiencing oxygen stress, and an

81 accumulation of DOM that is catabolized by pathways that require oxygenases. The $H B H$

82 ascribes the decline in $\mathrm{O}_{2}$ frequency distributions of suboxic and anoxic waters (Figures 2 and

83 S2) to fundamental biochemical properties of cells, particularly the mechanisms by which

84 oxidative enzymes cleave semi-labile organic matter, making it accessible to further oxidation.

85 Oxygen depletion by respiration in aquatic systems. How far can respiring marine bacteria

86 lower oxygen concentrations when they are provided with an ample supply of reductant for

87 respiration, as would be expected for plankton in the presence of an excess of labile organic

88 carbon? The Pasteur Point is an influential concept based on the observation that facultative

89 anaerobes switch to fermentation at ca. $2.2 \mu \mathrm{M} \mathrm{O}_{2}$, approximately an order of magnitude below

90 the average $\mathrm{K}_{\mathrm{m}}$ for oxygenases (Fig 1), steep declines in suboxic and anoxic water volumes in 
91 EBUS (Fig 2), and the ca. $25 \mu \mathrm{M}$ inflection in cumulative frequency distribution of DO

92 observations recorded in CCS (Fig. S2). Newer information suggests that the limits of bacterial

93 respiration are in the nanomolar range. This is consistent with the observation of high affinity

94 cytochromes that exhibit $\mathrm{O}_{2} \mathrm{~K}_{\mathrm{m}}$ between 3 and $200 \mathrm{nM}$ (8; Figure 1). Higher $\mathrm{O}_{2} \mathrm{Michaelis}$

95 constants have been sometimes been reported for marine bacteria, but it has been suggested that

96 higher values obtained with whole cells reflect diffusion limitation, which can be expected to

97 inflate apparent $\mathrm{O}_{2}$ Michaelis constants in proportion to cell sizes and respiration rates. Stolper et

98 al. showed that $E$. coli cells could grow at less than $3 \mathrm{nM} \mathrm{O}_{2}$, a sufficiently low concentration to

99 limit growth by diffusion, but high enough to sustain growth through $\mathrm{O}_{2}$ respiration (8). Our

100 meta-analysis of indicates that cells grown on highly labile carbon compounds such as glucose

101 display whole cell $\mathrm{O}_{2} \mathrm{~K}_{\mathrm{m}}$ values extends well into nanomolar $\mathrm{O}_{2}$ concentrations. We conclude

102 that a substantial background of observations and theory support the conclusion that the

103 respiration rate of chemoheterotrophic cells should not by limited by $\mathrm{O}_{2}$ at concentrations found

104 in ocean hypoxic zones or the Pasteur Point at ca. $2.2 \mu \mathrm{M}$.

105 The accumulation of hypoxic and scarcity of suboxic or anoxic volumes in the ocean nonetheless

106 suggest that negative feedbacks between oxygen decline and respiration may be at play. Direct

107 measurements of microbial $\mathrm{O}_{2} \mathrm{~K}_{\mathrm{m}}$ in natural systems are rare but available evidence point to $\mathrm{K}_{\mathrm{m}}$

108 values far higher than the nanomolar values reported from laboratory cultures with labile carbon

109 sources. Working in the Arabian Sea OMZ, Keil et al. (9) observed an apparent $\mathrm{K}_{\mathrm{m}}$ of $20 \mu \mathrm{M} \mathrm{O}_{2}$

110 for microbial community respiration. In the Nambian and Peruvian OMZ, Kalvelage et al. (10),

111 reported a linear decline in respiration rate between 20 and $0 \mu \mathrm{M} \mathrm{O}_{2}$. In Chesapeake Bay, a

112 hypoxia-prone system, microbial respiration rates saturate at $\left[\mathrm{O}_{2}\right]$ above $25 \mu \mathrm{M}(11)$, a pattern

113 that we have similarly found for the CCS OMZ (Figure S3). Holtappels et al. (12) further 
114 reported linear declines in respiration rates between 14 and $1 \mu \mathrm{M} \mathrm{O}_{2}$ in waters collected from a

115 fjord in Denmark. These results are surprising because researchers using the same methods have

116 also found many instances of $\mathrm{nM} \mathrm{K}_{\mathrm{m}}$ values for microbial respiration. This suggests a bimodal

117 distribution of $\mathrm{O}_{2} \mathrm{~K}_{\mathrm{m}}$ values that differ by upwards of three orders of magnitude. Telescoping out

118 further, global models of ocean $\mathrm{O}_{2}$ and carbon export converge on $\mathrm{K}_{\mathrm{m}}$ values of between 4 and

$11920 \mu \mathrm{M} \mathrm{O}_{2}$ in order to optimize fit between model and observations $(13,14)$. What accounts for

120 the disparity between accumulation of hypoxic water volumes, the $\mu \mathrm{M}$ scale $\mathrm{K}_{\mathrm{m}}$ 's reported from

121 natural systems and used to fit models, and $\mathrm{nM}$ scale $\mathrm{K}_{\mathrm{m}}$ 's predicted by respiratory oxidases?

122 Biochemistry offers a mechanistic explanation for this apparent disparity. There is evidence in

123 the scientific literature suggesting that microbial respiration of some types of organic matter is

124 slows when oxygen concentrations fall low enough to inhibit catabolic oxygenase enzymes.

125 Kroonman et al. (15), studying 3-chlorobenzoate degradation by the bacterium Alcaligenes,

126 reported two $\mathrm{K}_{\mathrm{m}}$ values for $\mathrm{O}_{2}$ uptake. They attributed the lower value $(65 \mathrm{nM})$ to respiration

127 and the higher value $(7-17 \mu \mathrm{M})$ to the activity of dioxygenases. Leahy and Olsen (16), studying

128 toluene degradation by Pseudomonads, also reported biphasic kinetics for toluene catabolism as

129 a function of oxygen concentration. The slope of the oxygen response declined with an inflection

130 at $20-30 \mu \mathrm{M} \mathrm{O}_{2}$. In both of these cases the behavior of the cultured cells oxidizing recalcitrant

131 compounds is remarkably similar to the generalized behavior of ocean ecosystems approaching

132 hypoxia.

133 To further explore the distribution of $\mathrm{O}_{2} \mathrm{~K}_{\mathrm{m}}$ values among biological reactions, we conducted a

134 metanalysis of published data, shown in Figure 1; Figure S1A; Table S1. For $\mathrm{O}_{2} \mathrm{~K}_{\mathrm{m}}$ values

135 reported in the literature, the median value for terminal respiratory oxidases was $350 \mathrm{nM}$, but for

136 other oxidase types the median value was $67 \mu \mathrm{M}$. The difference of $\sim 100$ fold in median values 
137 was supported by a p-value of $<2 \mathrm{e}-16$ in a t-test of the linear mixed-effect model coefficient

138 comparing the log-transformed $\mathrm{O}_{2} \mathrm{~K}_{\mathrm{m}}$ values (17). The bimodal distribution of $\mathrm{O}_{2} \mathrm{~K}_{\mathrm{m}}$ observed

139 at the enzyme scale is also repeated in whole cell studies. Cells that are grown on more complex

140 organic carbon sources have a median respiratory $\mathrm{K}_{\mathrm{m}}$ value of $20 \mu \mathrm{M}$, while cells grown on

141 highly labile organic carbon such as glucose have median $\mathrm{K}_{\mathrm{m}}$ of $690 \mathrm{nM}$ (Figure S1B).

142 Many enzymes that catalyze the biological breakdown of organic matter use oxygen as a

143 substrate, yielding partially oxidized products that are metabolized further through catabolic

144 pathways. These enzymes are often classified as either monooxygenases (mixed function

145 oxidases) or dioxygenases. Enzymes in both families evolved to use $\mathrm{O}_{2}$ as a substrate, but

146 monooxygenases incorporate a single oxygen atom into the substrate, reducing the second atom

147 to water, whereas dioxygenases typically add both atoms of the reacting $\mathrm{O}_{2}$ to the product. A

148 geochemically important example of a monooxygenase is the heme-dependent Mn peroxidase

149 that catalyzes oxidation of lignin, a phenolic oligomer. Fungal ligninases belong in the heme-

150 dependent peroxidase superfamily (18). Ligninases evolved in the Paleozoic, and it has been

151 postulated that their origin resulted in widespread biodegradation of wood, causing the end of the

152 carboniferous period, and rises in global atmospheric $\mathrm{CO}_{2}(19)$. Another superfamily of oxidases,

153 the flavin-dependent monooxygenases, are among the most diverse and prevalent proteins known.

154 They catalyze a wide range of reactions, for example hydroxylation, Baeyer-Villiger oxidation,

155 oxidative decarboxylation, epoxidation, desulfurization, sulfoxidation and oxidative denitration

156 (20). Many of the reactions catalyzed by flavin-dependent monooxygenases initiate the

157 catabolism of compounds that are otherwise recalcitrant to oxidation. These enzymes share a

158 common mechanism in which reduced flavin reacts with oxygen to produce a flavin C4a-

159 (hydro)peroxide that then reacts with electrophilic or nucleophilic substrates, typically resulting 
160 in the consumption of one diatomic oxygen molecule, the addition of an oxygen atom to the

161 substrate, and the release of water. Also important are the dioxygenases, which belong to a

162 different protein family also feature prominently in DOM degradation particularly for aromatic

163 compounds. These protein families came to the attention of oceanographers recently when it was

164 discovered that cells of one of the important oceanic bacterial clades, SAR202, harbor expanded

165 clusters of paralogous genes from both of these protein types (21). It has been proposed that

166 these enzymes participate in the oxidation of semi-labile organic matter, initiating its breakdown.

167 The meta-analysis of $\mathrm{O}_{2} \mathrm{~K}_{\mathrm{m}}$ values presented in Figure 1 suggests that micromolar DO sensitivity

168 is ubiquitous across metabolic processes. Among the "other oxidase" types, we observed no clear

169 trends that associated $\mathrm{O}_{2} \mathrm{~K}_{\mathrm{m}}$ values with protein families sorted by COGs or other precise

170 functional groups, such as enzyme commission classifications. In contrast, cytochrome

171 respiratory proteins with heme cofactors consistently displayed a much higher affinity for

172 oxygen that other protein types. Phylogenetically, the distribution of $\mathrm{O}_{2} \mathrm{~K}_{\mathrm{m}}$ values included

173 diverse bacteria, including Proteobacteria, Actinobacteria, Firmicutes, and Cyanobacteria, as

174 well as eukaryotic organisms including fungi, humans, and other chordates. $\mathrm{O}_{2} \mathrm{~K}_{\mathrm{m}}$ values showed

175 a 100-fold difference between respiratory and non-respiratory oxidases regardless of taxonomic

176 group. We conclude that this pattern is robust to phylogenetic bias in $\mathrm{O}_{2} \mathrm{~K}_{\mathrm{m}}$ value sampling.

177 While our focus in the current work is marine systems, the $\mathrm{HBH}$ in principle applies to all

178 ecosystems.

179 The role of oxidases in organic matter degradation. Oceanographers classify organic matter

180 by its half-life, frequently using the category "labile dissolved organic matter" (LDOM) to

181 describe dissolved organic matter that is oxidized in minutes to hours, or at most a few days,

182 while the term "semi-labile" (SLDOM), and sometime "recalcitrant" are used to refer to 
183 dissolved organic matter that persists longer, but is eventually oxidized. Here we introduce a new

184 term, "oxygen-dependent DOM" (ODDOM) to describe DOM that is catabolized via reactions

185 that require the activity of oxygenases and thus are susceptible to inhibition when $\mathrm{O}_{2}$

186 concentrations reach values in the range of ca. 10-100 $\mu \mathrm{M}$. We'll confine the discussion to

187 dissolved forms of organic matter, although most organic matter enters ecosystems as particulate

188 organic matter (POM) and is subsequently converted to DOM before being used by

189 microorganisms. Implicit in the above categories is the idea that different kinds of organic

190 matter are accessible to biological oxidation through different mechanisms and at different rates.

191 The HBH is consistent with the distribution of ocean anoxic zones if one assumes organic

192 matters supplies are uneven. If LDOM is oversupplied relative to oxygen, for example by high

193 rates of export production in systems with restricted circulation, then the activities of respiratory

194 terminal cytochrome complexes would be expected to readily draw down DO to nM

195 concentrations in accordance with their $\mathrm{nM} \mathrm{K} \mathrm{K}_{\mathrm{m}}$ values. In natural systems, LDOM are rapidly

196 depleted. As hypothesized, the activities of non-respiratory oxidases limit the supply of reductant

197 to respiratory oxidases. This acts as a bottleneck that slows the rate of respiration as DO declines.

198 With sufficient time, DO should reach minimum values as expected from $\mathrm{nM} \mathrm{K}_{\mathrm{m}}$ values of

199 respiratory oxidases. Such conditions can be met in the core of OMZs that have been isolated

200 from the atmosphere over decadal to century time scales, and evidence of this can be seen in Fig.

202 The large disparity in $\mathrm{K}_{\mathrm{m}}$ 's we report between respiratory oxygenases and other oxygenase types

203 has implications for microbial cell evolution and metabolic regulation at the cellular level.

204 Inside of cells respiratory oxygenases could outcompete other oxygenases, exacerbating the

205 slowing of some oxygen-dependent cellular processes at low oxygen. To avoid this, cells may 
have evolved metabolic regulation that avoids such competitive interactions, for example by

207 shifting to alternate electron acceptors before $\mathrm{O}_{2}$ is depleted (22). This topic, which needs

208 exploration, could help us understand how microbial cells have adapted to suboxic environments,

209 which are far more common in the ocean than anoxic environments.

210 Testing the HBH. The HBH sets forth a number of central predictions that are testable by

211 experimentation, observation, and modeling. The impact of biphasic oxygen dependence

212 predicted by the $\mathrm{HBH}$ should be manifested as a broad potential for oxygen to limit microbial

213 respiration across hypoxic systems in the range of oxygenase $\mathrm{K}_{\mathrm{m}}$ values (median value $67 \mu \mathrm{M}$ ),

214 when LDOM is depleted, but not if excess LDOM is present. To test that prediction, we

215 measured rates of respiration (oxygen uptake) in water samples from the Northern California

216 Current System OMZ, where DO minimum reach only $\sim 5 \mathrm{M}$, well above canonical $\mathrm{nM} \mathrm{K}_{\mathrm{m}}$ for

217 cytochrome oxidases. DO was increased by the simple expedient of allowing air to be

218 momentarily entrained during filling (Figure S3). In our experiments, and other similar

219 experiments we found among published work, the addition of DO caused respiration rates to rise

220 relative to controls. This observation could be attributed to the limitation of respiration by

221 diffusion (20), but alternatively, it could result from mechanisms described in the HBH model

222 we propose.

223 There are many other experimental avenues to testing the HBH that have not been explored.

224 Figure S2 scratches the surface of what could done with field experiments and mesocosms to

225 verify predictions of the $\mathrm{HBH}$. For example, experiments that test the biological availability of

226 DOM at high (e.g. $200 \mu \mathrm{M}$ ) and moderate (e.g. $20 \mu \mathrm{M})$ DO could challenge these ideas.

227 Mechanisms invoked by the HBH would lead to changes in the chemical composition of DOM

228 as DO declines: the ratio of LDOM to ODDOM should decrease as DO approaches the $\mathrm{K}_{\mathrm{m}}$ 
229 values of catabolic oxygenase enzymes for $\mathrm{O}_{2}$. Measurements of DOM chemistry could

230 determine whether these changes occur as predicted. ODDOM, a term coined herein to segregate

231 DOM into categories by chemical composition and oxygenase involvement in catabolism, is at

232 present a theoretical concept, albeit grounded in the fundamentals of biochemistry. Although

233 chemical oceanographers do not at present measure ODDOM, in principle methods such as high

234 resolution NMR, HPLC, and LC-MS/MS could be applied for this purpose, and could be used to

235 test predictions of the HBH. Omics approaches, including functional genomics, provide an

236 avenue that could be applied in marine systems to measure the expression and activity of

237 oxygenase enzymes involved in ODDOM metabolism, and to characterize of the responses of

238 plankton cells and communities to suboxia.

239 The HBH has broader implications that could be explored with global data. It posits that rates of

240 oxygen loss and DOM oxidation slow as DO approaches hypoxia, setting the upper bounds for

241 the size of oceanic anoxic zones and organic carbon pools within. This can be evaluated in detail

242 by modeling studies that test the sensitivity of model-data comparisons to changes in

243 assumptions about microbial kinetic constants for oxygen.

244 Alternatives to the HBH. While we propose $\mathrm{HBH}$ to explain declines in oxygen frequency

245 distributions at unexpected high values (Figs. 2 and S2) and the rarity of suboxia and anoxia

246 across productive, low oxygen EBUS, alternate scenarios could explain this phenomenon. For

247 example, consistent barriers to oxygen diffusion to the terminal oxidases of respiratory systems,

248 or feedback mechanisms involving the production of sulfides and/or depletion of DO in

249 microhabitats, or oxygen limitation of metazoan grazing, could play a role in suppressing

250 respiration at low oxygen concentrations. Alternatively, there may be constraints on supply of 
251 organic carbon or positive feedbacks on the resupply of DO by advection or diffusion as DO

252 approaches hypoxia.

253 Public interest and policy. The relevance of this issue to public interests in ecosystem

254 management could not be more profound. Ocean deoxygenation, the decline in ocean oxygen

255 inventories, has emerged as a leading pathway for climate change impacts in the sea. This

256 decline has been linked with expansion of hypoxic and anoxic zones. Oxygen deficient zones are

257 hotspots of biogeochemical transformations whose growth can have profound impacts on marine

258 biodiversity, vertical organic carbon flux, the sustainability of fisheries and feedbacks that

259 govern ocean nitrogen budgets and flux of radiatively active $\mathrm{N}_{2} \mathrm{O}$. The ability to accurately

260 forecast such ecosystem changes is central for informing responsive climate change mitigation

261 and adaptation policies. However, the disagreement between observations and the textbook

262 understanding of microbial respiration raises fundamental questions about the mechanisms that

263 underlie our conceptual and numerical models of the ocean dynamics as climate change

264 intensifies. The HBH offers a testable framework for examining a potentially flawed

265 fundamental principle that governs our thinking about OMZ formation. If this hypothesis is

266 correct, it will open previously overlooked avenues of research at the intersection of oxygenase

267 enzyme evolution, oxygenase-dependent metabolism in microbial communities, and OMZ

268 dynamics.

269 Conclusion. If these ideas have the power to even partially explain the kinetics of ocean oxygen

270 depletion, they could contribute to a better understanding of climate change impacts on ocean

271 deoxygenation and DOM chemistry. The data in Fig. 1 show us that the HBH is founded on

272 sound basic principles, but the impact of oxygenase "barrier" we describe is relative to many

273 other processes, mentioned above, that can also slow respiration, most notably diffusion. Sorting 
274 out the magnitude of catabolic oxygenase enzyme contributions to DOM oxidation, whether that

275 number be large or small, will help us assess how the trajectories of aquatic systems

276 experiencing oxygen declines are shaped by the fundamental biochemistry described in the HBH.

\section{MATERIAL AND METHODS}

278 Data collection. Scientific literature was mined for characterized oxygenase enzymes with

279 published $\mathrm{K}_{\mathrm{m}}$ values for dissolved oxygen for both individual enzyme assays as well as whole

280 cell assays (Table S1). Metadata, including enzyme name and host scientific organism name,

281 were extracted from each article. We used a combination of BRENDA enzyme database, uniprot

282 protein database, and KEGG database searches to determine putative protein accessions, KEGG

283 ortholog IDs, and EC numbers associated with the published enzyme data. Repeated entries for

284 the same organism-protein pairs were included due to the various testing conditions per study.

285 Basin and global inventories of DO volumes were compiled from the World Ocean Atlas 2018

286 (https://www.ncei.noaa.gov/products/world-ocean-atlas. Dissolved oxygen observations (5-

287 400m) from CTD profiles were compiled from Chan et al. 2008, https://www3.mbari.org/bog/,

288 and https://www.calcofi.org/ for the northern $(n=107,0321950$ to 2006), central ( $n=4,3721997$ -

289 2013), and southern ( $\mathrm{n}=4,372$ 1997-2013) CCS, respectively.

290 Respiration rate experiment. Water samples were drawn from above and within the CCS OMZ

$291\left(4647.56^{\circ} \mathrm{N}, 12511.83^{\circ} \mathrm{W}, 1000 \mathrm{~m}\right.$ station depth) and filled into 300ml borosilicate glass BOD

292 bottles that each contained an oxygen optode dot (PreSens Precision Sensing GmbH). On filling,

293 DO in a subset of samples initial [DO] were increased by allowing air to be entrained momen-

294 tarily in the Niskin outflow tubing. Bottles were incubated in a $\sim 6^{\circ} \mathrm{C}$ water bath in the dark. DO

295 change over 48 was measured through the glass via detection of phase shift luminescence. 
297 Boxplot generation. Km-DO values were split into two primary groups dependent upon general

298 protein function, either respiratory oxidases or non-respiratory oxidases. $\mathrm{K}_{\mathrm{m}}$-DO values were

299 also gathered for whole cells, whereby labile and semi-label carbon sources were compared,

300 mirroring the respiratory and non-respiratory individual enzyme assays. Plots were generated

301 with the grouped Km-DO values using R v4.0.2 (23) and the ggplot2 (24). A linear mixed

302 effects model was used to control for repeated $\mathrm{O}_{2} \mathrm{Km}$ measurements from the same organism,

303 with the formula $\log \left(\mathrm{K}_{\mathrm{m}}\right) \sim$ oxidase type $+(1 \mid$ organism $)$. The model was fit using maximum

304 likelihood, and the t-test to confirm significant difference of the coefficient for oxidase type was

305 done using Satterthwaite's method for degrees of freedom (17). Log (natural) transformed values

306 were used to approximate normality in the data. $\mathrm{R}$ code for this analysis can be found at github

307 repo: https://github.com/davised/HBH-2021.

308 ACKNOWLEDGEMENTS

309 We thank the reviewers, John Coates and Dave Valentine, for their many useful comments. John

310 Coates offered the important insight that intracellular competition with respiratory oxygenases

311 could contribute to the inhibition of non-respiratory oxygenases. This work was funded by the

312 National Science Foundation grant DEB-1639033, NOAA grant NA18NOS4780169, a SciRIS

313 award from the Oregon State University College of Science, and a grant from Simons

314 Foundation International. No authors declare any real or perceived financial conflicts of interests. 


\section{REFERENCES (24/25)}

316 1. Levin LA. 2018. Manifestation, drivers, and emergence of open ocean deoxygenation.

317 Annual Review of Marine Science, Vol 10 10:229-260.

318 2. Deutsch C, Brix H, Ito T, Frenzel H, Thompson L. 2011. Climate-forced variability of $319 \quad$ ocean hypoxia. Science $333: 336-339$.

320 3. Revsbech NP, Larsen LH, Gundersen J, Dalsgaard T, Ulloa O, Thamdrup B. 2009.

321 Determination of ultra-low oxygen concentrations in oxygen minimum zones by the 322 STOX sensor. Limnology and Oceanography-Methods 7:371-381.

323 4. Longmuir IS. 1954. Respiration rate of bacteria as a function of oxygen concentration.

$324 \quad$ Biochem:81-87.

325 5. Zakem EJ, Follows MJ. 2017. A theoretical basis for a nanomolar critical oxygen 326 concentration. Limnology and Oceanography 62:795-805.

327 6. Cavan EL, Trimmer M, Shelley F, Sanders R. 2017. Remineralization of particulate

328 organic carbon in an ocean oxygen minimum zone. Nat Commun 8:14847.

329 7. Robinson C. 2019. Microbial Respiration, the Engine of Ocean Deoxygenation. Frontiers $330 \quad$ in Marine Science 5.

331 8. Stolper DA, Revsbech NP, Canfield DE. 2010. Aerobic growth at nanomolar oxygen 332 concentrations. Proceedings of the National Academy of Sciences of the United States of $333 \quad$ America 107:18755-18760.

334 9. Keil RG, Neibauer JA, Biladeau C, van der Elst K, Devol AH. 2016. A multiproxy 335 approach to understanding the "enhanced" flux of organic matter through the oxygen336 deficient waters of the Arabian Sea. Biogeosciences 13:2077-2092. 
337 10. Kalvelage T, Lavik G, Jensen MM, Revsbech NP, Loscher C, Schunck H, Desai DK,

338 Hauss H, Kiko R, Holtappels M, LaRoche J, Schmitz RA, Graco MI, Kuypers MMM.

339 2015. Aerobic microbial respiration In oceanic oxygen minimum zones. Plos One 10.

340 11. Sampou P, Kemp WM. 1994. Factors Regulating Plankton Community Respiration in

341 Chesapeake Bay. Marine Ecology Progress Series 110:249-258.

342 12. Holtappels M, Tiano L, Kalvelage T, Lavik G, Revsbech NP, Kuypers MMM. 2014.

343 Aquatic respiration rate measurements at low oxygen concentrations. Plos One 9.

344 13. Laufkotter C, John JG, Stock CA, Dunne JP. 2017. Temperature and oxygen dependence

345 of the remineralization of organic matter. Global Biogeochemical Cycles 31:1038-1050.

346 14. DeVries T, Weber T. 2017. The export and fate of organic matter in the ocean: New

347 constraints from combining satellite and oceanographic tracer observations. Global

$348 \quad$ Biogeochemical Cycles 31:535-555.

349 15. Krooneman J, Wieringa EB, Moore ER, Gerritse J, Prins RA, Gottschal JC. 1996.

350 Isolation of Alcaligenes sp. strain L6 at low oxygen concentrations and degradation of 3-

351 chlorobenzoate via a pathway not involving (chloro)catechols. Appl Environ Microbiol

$352 \quad 62: 2427-2434$.

353 16. Leahy JG, Johnson GR, Olsen RH. 1997. Cross-regulation of toluene monooxygenases

354 by the transcriptional activators TbmR and TbuT. Appl Environ Microbiol 63:3736-9.

355 17. Kuznetsova A, Brockhoff PB, Christensen RHB. 2017. lmerTest Package: Tests in Linear $356 \quad$ Mixed Effects Models. 2017 82:26.

357 18. Fox NK, Brenner SE, Chandonia JM. 2014. SCOPe: Structural Classification of Proteins358 -extended, integrating SCOP and ASTRAL data and classification of new structures.

$359 \quad$ Nucleic Acids Res 42:D304-309. 
360 19. Floudas D, Binder M, Riley R, Barry K, Blanchette RA, Henrissat B, Martinez AT,

361 Otillar R, Spatafora JW, Yadav JS, Aerts A, Benoit I, Boyd A, Carlson A, Copeland A,

362 Coutinho PM, de Vries RP, Ferreira P, Findley K, Foster B, Gaskell J, Glotzer D,

363 Gorecki P, Heitman J, Hesse C, Hori C, Igarashi K, Jurgens JA, Kallen N, Kersten P,

364 Kohler A, Kues U, Kumar TK, Kuo A, LaButti K, Larrondo LF, Lindquist E, Ling A,

365 Lombard V, Lucas S, Lundell T, Martin R, McLaughlin DJ, Morgenstern I, Morin E,

366 Murat C, Nagy LG, Nolan M, Ohm RA, Patyshakuliyeva A, et al. 2012. The Paleozoic

367 origin of enzymatic lignin decomposition reconstructed from 31 fungal genomes. Science

$368 \quad 336: 1715-1719$.

369 20. Huijbers MM, Montersino S, Westphal AH, Tischler D, van Berkel WJ. 2014. Flavin

370 dependent monooxygenases. Arch Biochem Biophys 544:2-17.

371 21. Landry Z, Swan BK, Herndl GJ, Stepanauskas R, Giovannoni SJ. 2017. SAR202

372 Genomes from the Dark Ocean Predict Pathways for the Oxidation of Recalcitrant

373 Dissolved Organic Matter. mBio 8.

374 22. Kits KD, Klotz MG, Stein LY. 2015. Methane oxidation coupled to nitrate reduction

375 under hypoxia by the Gammaproteobacterium Methylomonas denitrificans, sp nov type

376 strain FJG1. Environmental Microbiology 17:3219-3232.

377 23. Team RC. 2020. R: A language and environment for statistical computing. R Foundation

378 for Statistical Computing, Vienna, Austria https://www.R-project.org/.

379 24. Wickham H. 2016. Elegant Graphics for Data Analysis. Springer-Verlag New York. 


\section{FIGURES}

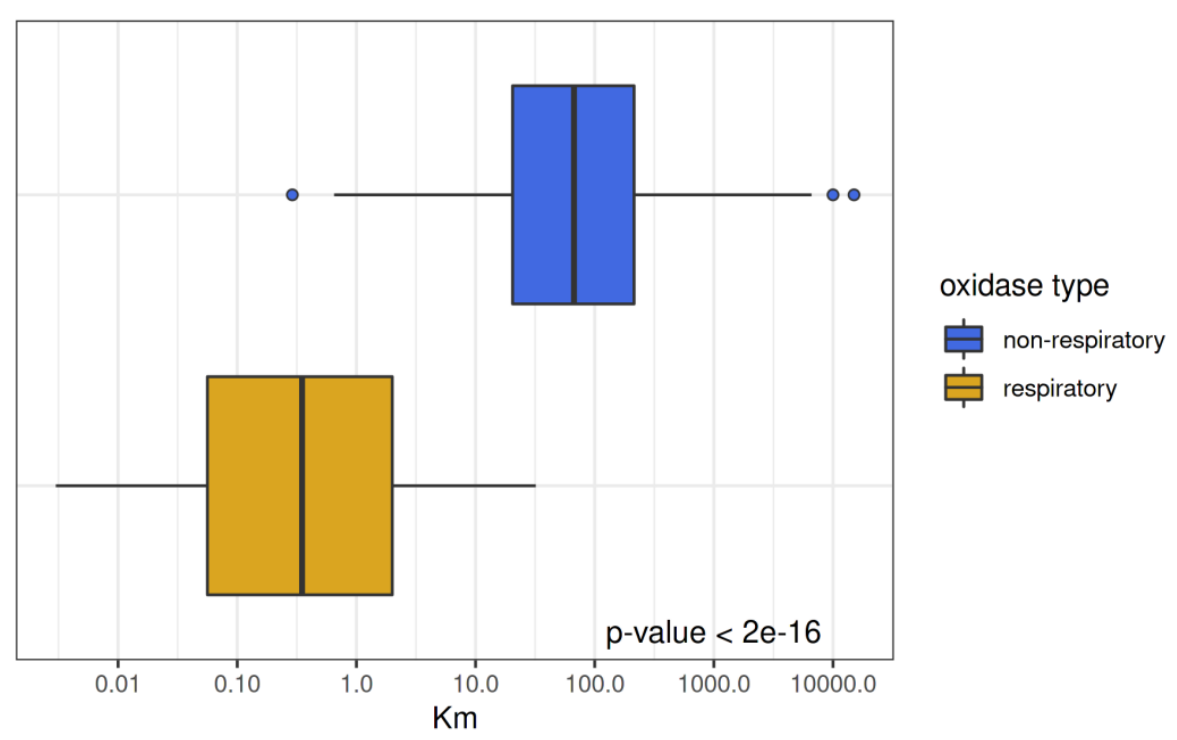

385 Figure $1 . \mathrm{K}_{\mathrm{m}}$ values are significantly smaller in respiratory oxidases compared to other

386 oxygenases. $\mathrm{K}_{\mathrm{m}}$-DO (dissolved oxygen) values for respiratory oxidases (yellow; $\mathrm{n}=109$ ) and

387 other oxygenases (blue; $\mathrm{n}=890$ ) are depicted on a $\log 10$ scale. The relatively high (e.g. $\left.10^{1} \mu \mathrm{M}\right)$

$388 \mathrm{~K}_{\mathrm{m}}$ values reported for oxidase enzymes indicate a potential bottleneck in the supply of electrons

389 from organic matter to respiration. The reported p-value is from a t-test using the Satterthwaite

390 approximations to degrees of freedom of a linear mixed model fit by maximum likelihood. Data

391 and citations can be found in Table S1. 

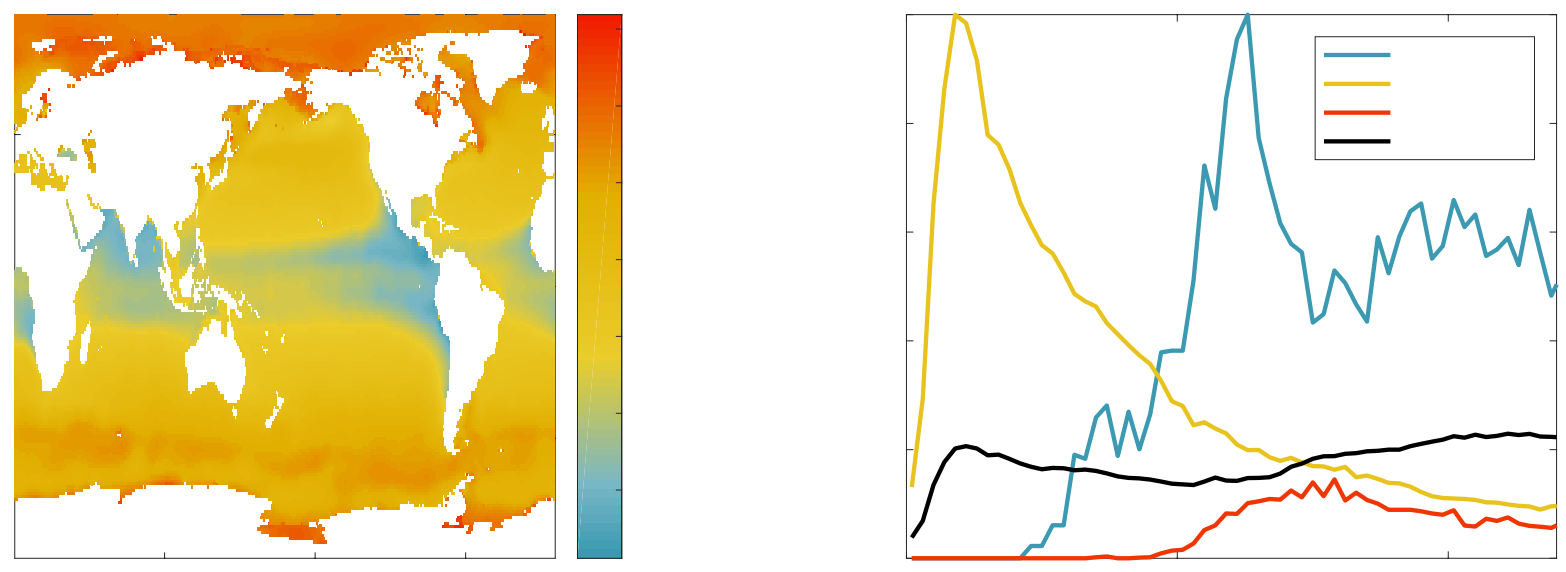

$\mu$
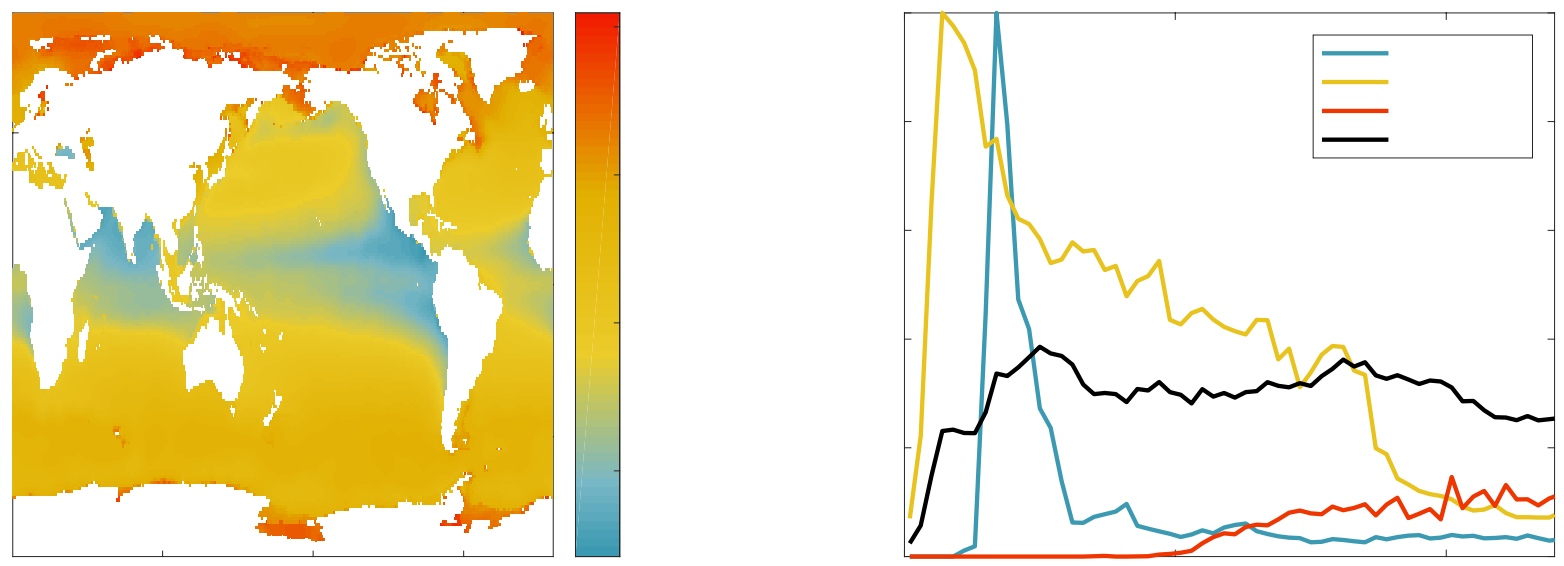

393 Figure 2. Climatological DO concentrations and distribution of ocean volume across DO

394 concentrations relationships for the California Current System (CCS), Eastern Tropical Pacific

395 (EastTropPac), Eastern Tropical Atlantic (EastTropAtl) and global ocean. (A) 0-400 m,

396 represents generally annual to decadal-scale processes, relative to ventilation and biomass

397 formation by photosynthesis, (B) 0-1000 m, encompasses decadal to centennial-scale processes. 
401 Table S1. Literature reports of $\mathrm{K}_{\mathrm{m}}$ values for oxygenase enzymes and terminal respiratory

402 oxidases used to construct Figs 1 and S1.

404 Fig. S1. Oxidase density plot. This plot illustrates the distribution of oxygenase $\mathrm{K}_{\mathrm{m}}$ values

405 reported in the literature for respiratory and non-respiratory oxidases (A) compared to whole cell

406 assays including labile and semi-labile carbon sources (B).

408 Fig. S2. Cumulative frequency distribution of DO observations from continental shelf depths (5-

$409400 \mathrm{~m}$, i.e. above the OMZ) for the northern $(-)$, central $(-)$, and southern $(-)$ California

410 Current System (CCS). Note the rarity of DO observations $<25 \mu \mathrm{M}$ and an apparent hinge in the

411 frequency of observations as DO increases beyond that concentration.

412 Fig. S3. Examples of respiration rates from field collected samples that exhibited non-saturating

413 dynamics at 10 's of $\mathrm{uM}\left[\mathrm{O}_{2}\right]$. In each instance, respiration rates were assayed in samples where

$414\left[\mathrm{O}_{2}\right]$ was manipulated independently. Data from the CCS were measured via $\mathrm{O}_{2}$ optode equipped 415 glass bottles from water samples collected within the OMZ. Oxygen was increased by allowing 416 air to be momentarily entrained as bottles were filled. 
bioRxiv preprint doi: https://doi.org/10.1101/2021.05.17.444596; this version posted May 18, 2021. The copyright holder for this preprint (which was not certified by peer review) is the author/funder, who has granted bioRxiv a license to display the preprint in perpetuity. It is made available under aCC-BY 4.0 International license.

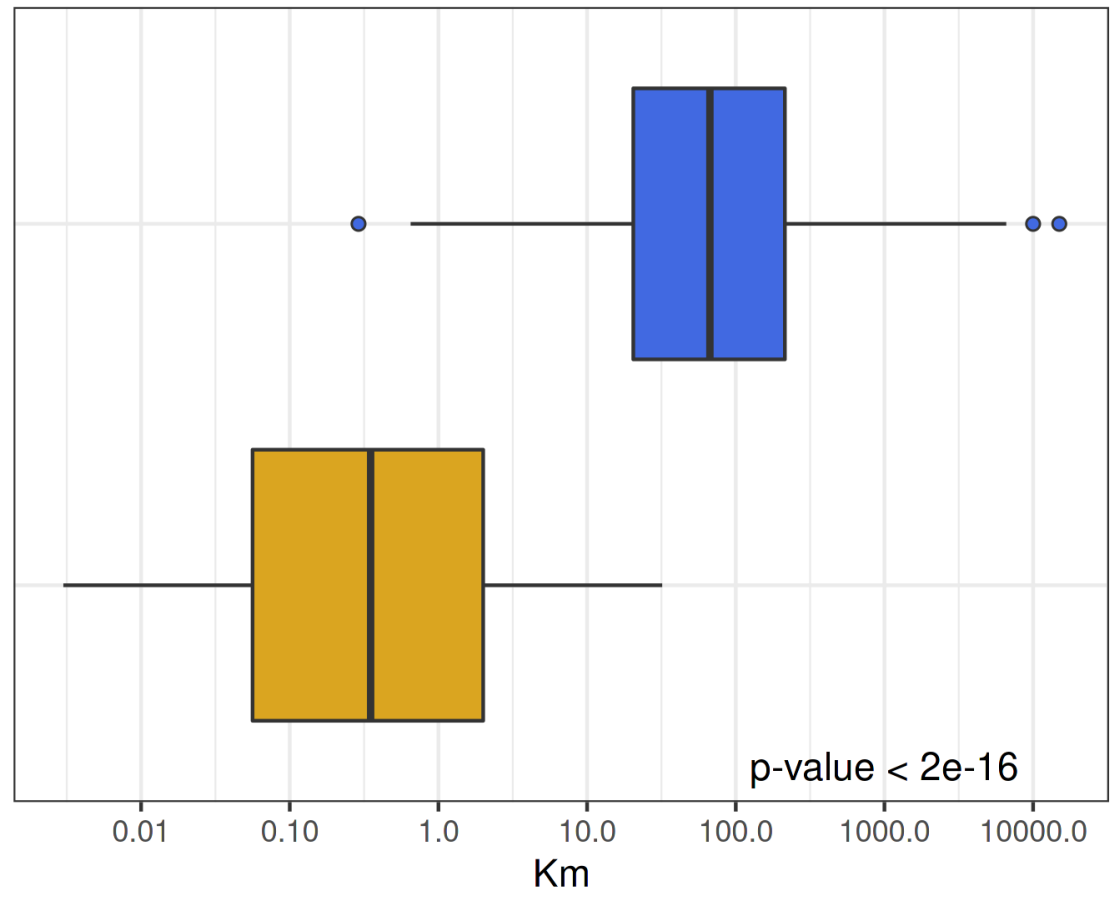

oxidase type

non-respiratory

它 respiratory 
Climatological 02 [0-400 m]

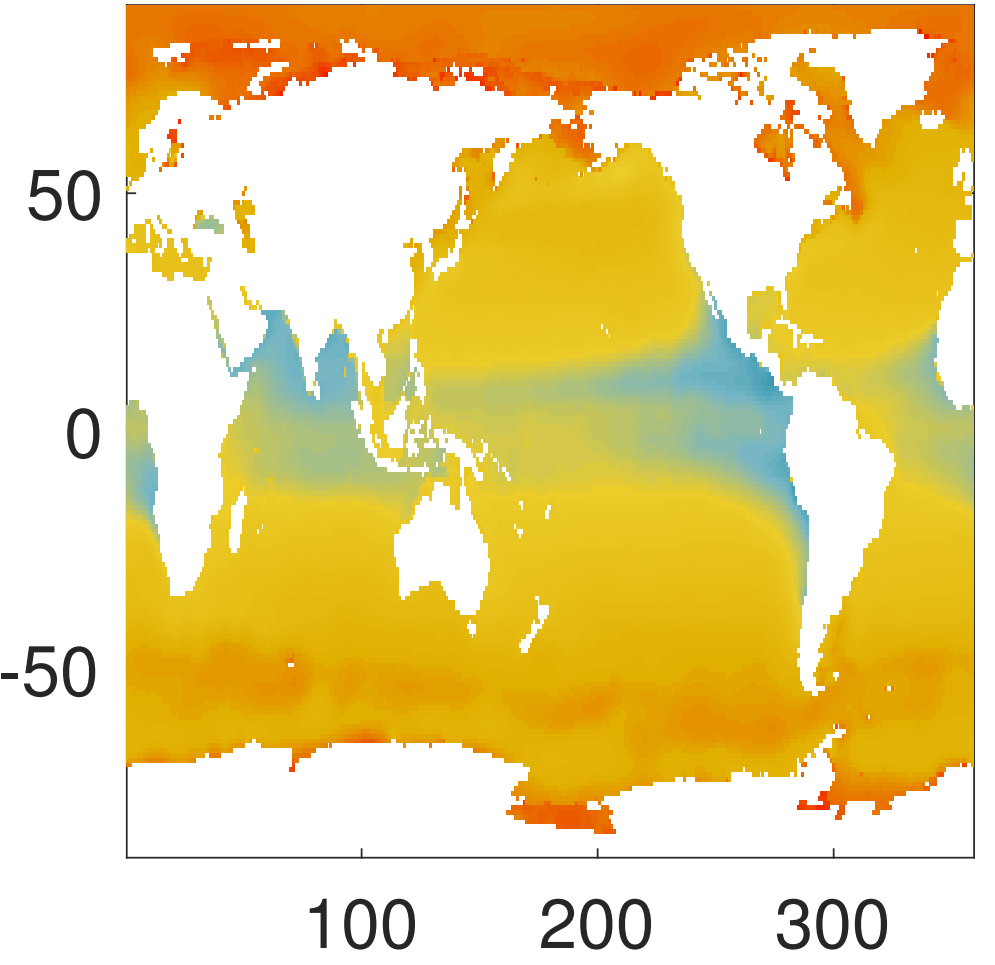

Climatological 02 [0-1000 m]

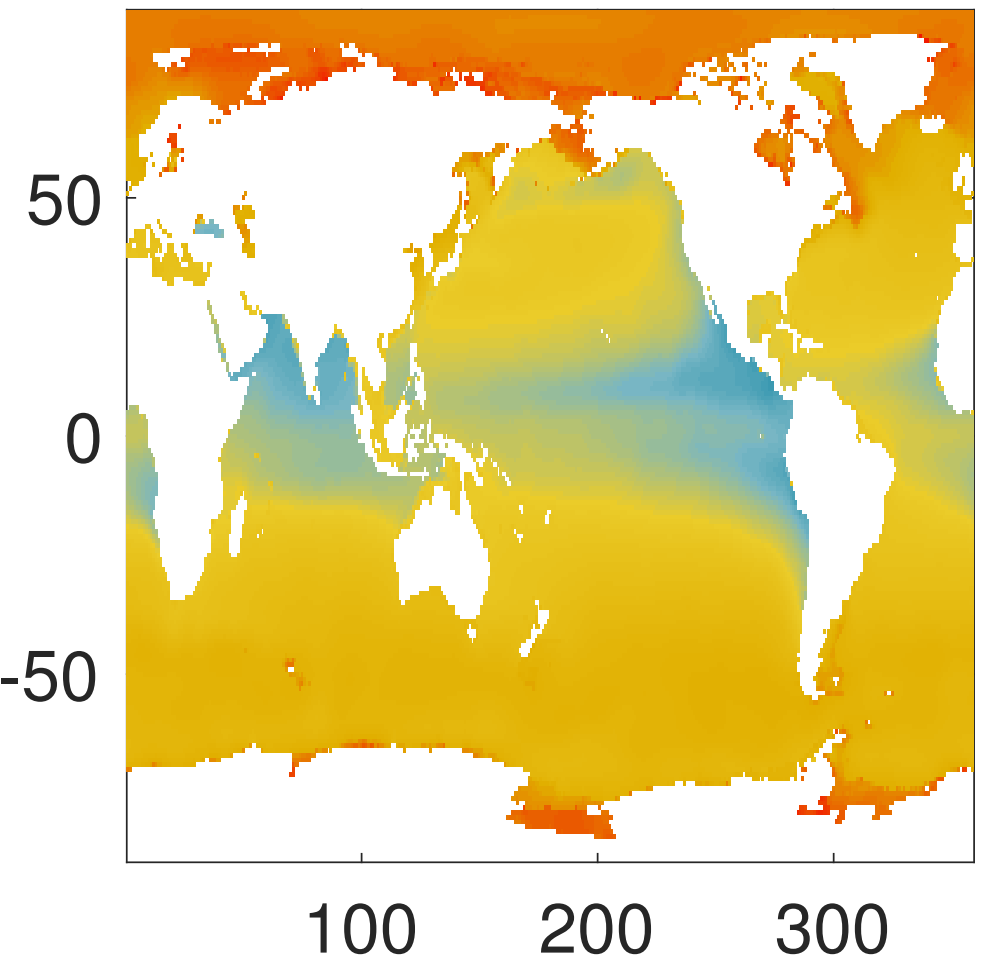

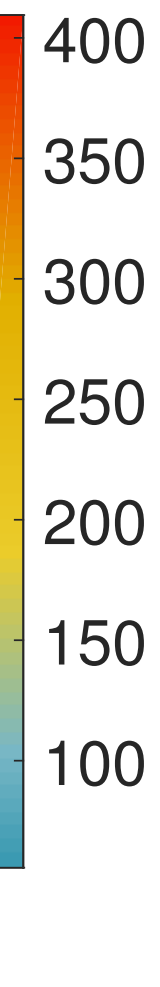

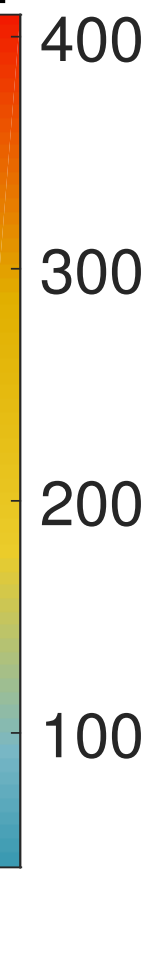

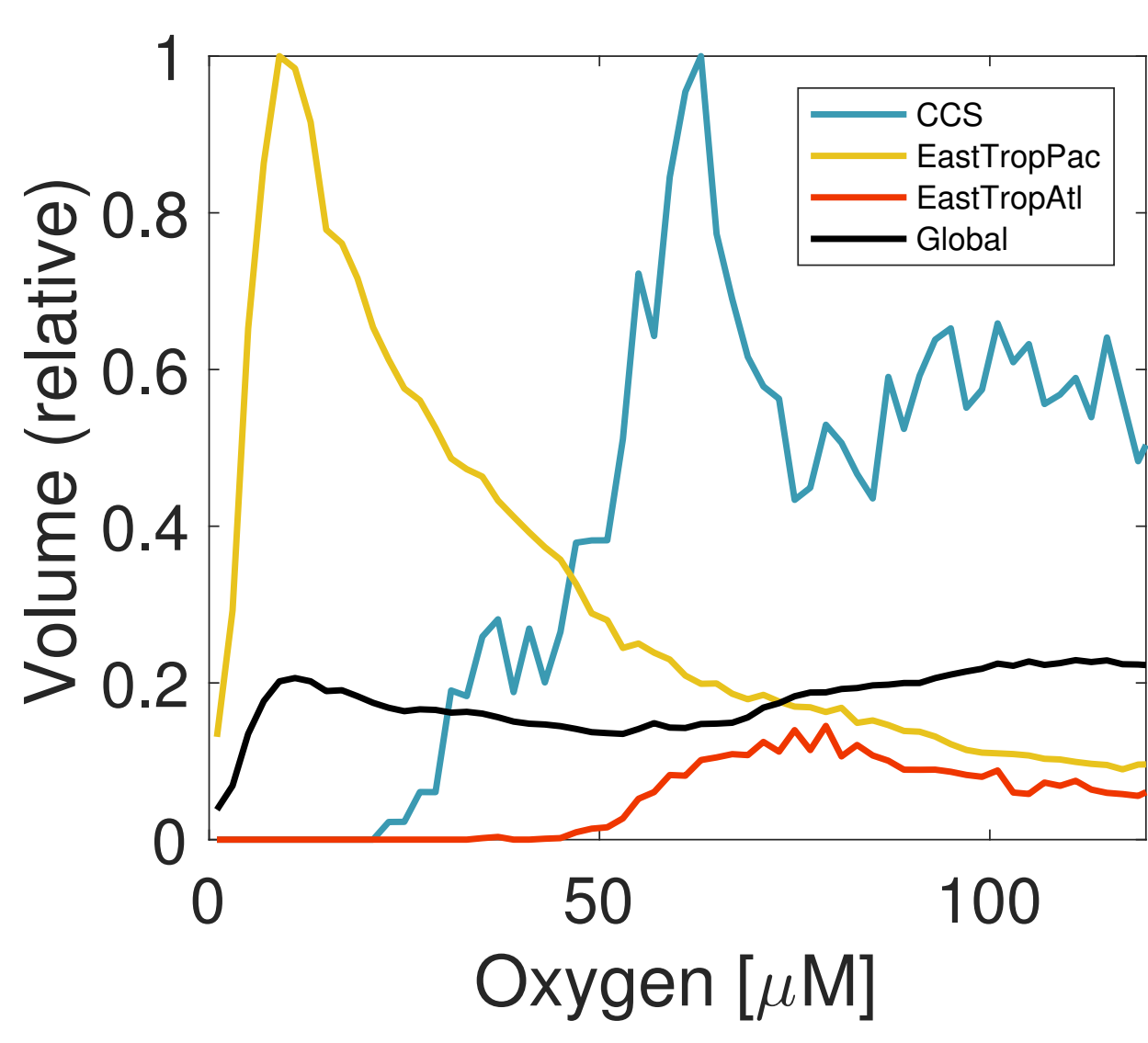

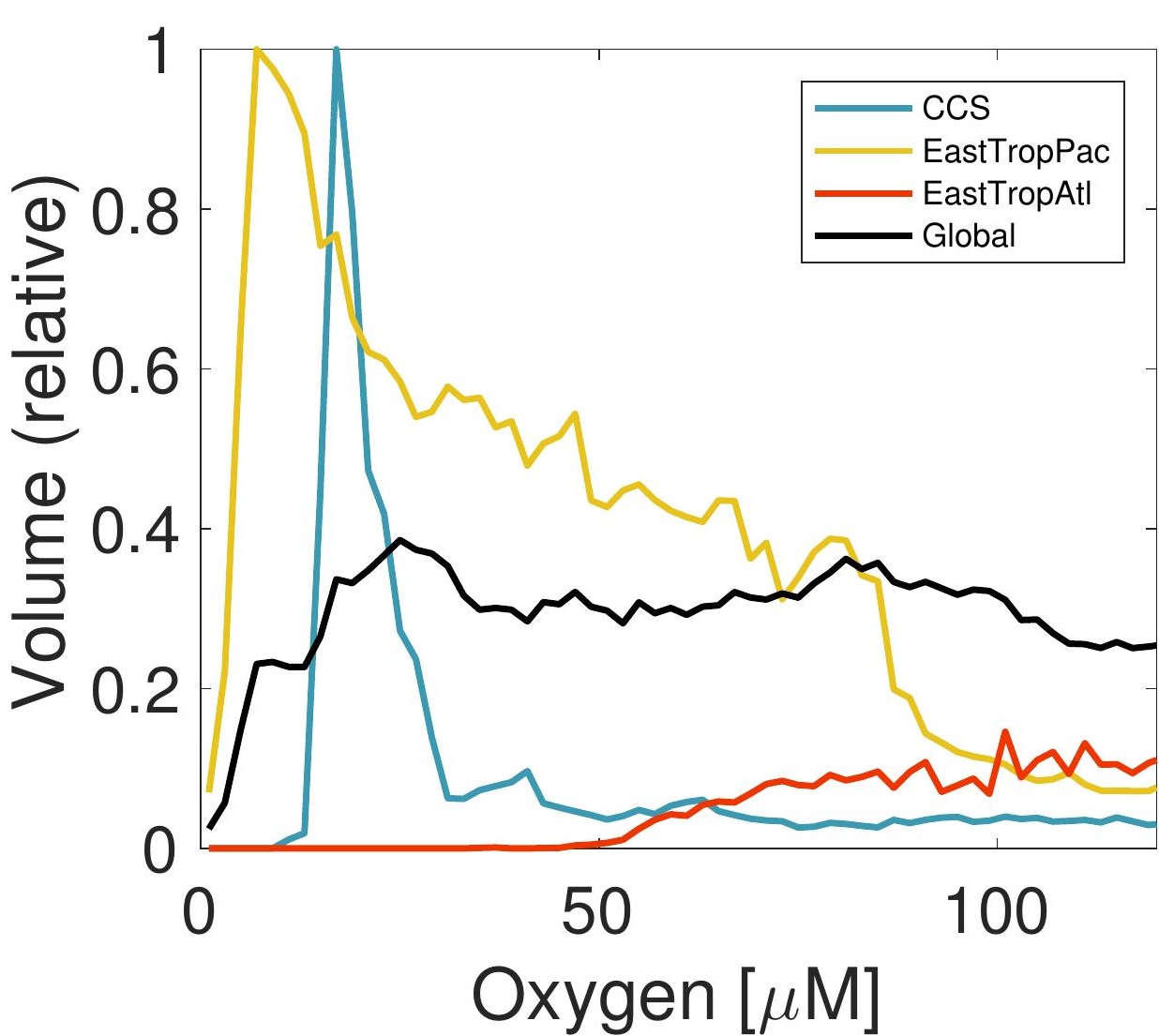

